\title{
MOTIVASI DAN KETERAMPILAN PEMAHAMAN TERHADAP KEMAMPUAN PEMECAHAN MASALAH MATEMATIKA DENGAN STRATEGI THINK TALK WRITE
}

\author{
Putri Okti Rizqiyani $^{1}$, Wikan Budi Utami ${ }^{2}$, Isnani ${ }^{3}$ \\ putri.rz18@gmail.com,wikan.piti@gmail.com, Isnani.ups@gmail.com \\ 1,2,3 Universitas Pancasakti Tegal
}

\begin{abstract}
This study aims to analyze how the influence of 1) motivation on mathematical problem solving skills with Think Talk Write strategy, 2) skills of understanding of mathematical problem solving skills with Think Talk Write strategies, 3) motivation and skills understanding of mathematical problem solving skills with Think Talk Write strategies. Data collection techniques carried out in the experimental class namely class VII D and class VII E using tests, questionnaires, and observations. The test instrument for problem solving ability amounted to 10 items, the questionnaire amounted to 30 items, while the observation instrument amounted to 15 items. Test instruments and questionnaires were first tested in the trial class that is class VII $\mathrm{C}$ to determine validity and reliability. Data analysis using a simple linear regression test and multiple regression, with a significance level of $5 \%$. The results were obtained 1) motivation influences the ability of mathematical problem solving with Think Talk Write strategy with a degree of influence $60.59 \%, 2$ ) comprehension skills affect the ability to solve mathematical problems with Think Talk Write strategies with an effect of $59.3 \%, 3)$ motivation and comprehension skills affect the ability to solve mathematical problems with the Think Talk Write strategy with a $65.99 \%$ effect.
\end{abstract}

Keywords: motivation, understanding skills, mathematical problem solving ability, Think Talk Write strategy

\begin{abstract}
Abstrak
Penelitian ini bertujuan untuk menganalisis bagaimana pengaruh 1) motivasi terhadap kemampuan pemecahan masalah matematika dengan strategi Think Talk Write, 2) keterampilan pemahaman terhadap kemampuan pemecahan masalah matematika dengan strategi Think Talk Write, 3) motivasi dan keterampilan pemahaman terhadap kemampuan pemecahan masalah matematika dengan strategi Think Talk Write. Teknik pengumpulan data dilakukan pada kelas eksperimen yaitu kelas VII D dan kelas VIIE dengan menggunakan tes, angket, dan observasi. Instrumen tes kemampuan pemecahan masalah berjumlah 10 butir soal uraian, instrumen angket berjumlah 30 item pernyataan, sedangkan instrumen observasi berjumlah 15 item. Instrumen tes dan angket terlebih dahulu diujikan ke kelas uji coba yaitu kelas VII C untuk mengetahui validitas dan reliabilitas. Analisis data menggunakan uji regresi linier sederhana dan uji regresi ganda, dengan taraf signifikansi 5\%. Hasil penelitian diperoleh 1) motivasi berpengaruh terhadap kemampuan pemecahan masalah matematika dengan strategi Think Talk Write dengan besar pengaruhnya $60,59 \%$,2) keterampilan pemahaman berpengaruh terhadap kemampuan pemecahan masalah matematika dengan
\end{abstract}


strategi Think Talk Write dengan besar pengaruhnya 59,3\%, 3) motivasi dan keterampilan pemahaman berpengaruh terhadap kemampuan pemecahan masalah matematika dengan strategi Think Talk Write dengan besar pengaruhnya $65,99 \%$.

Kata kunci: motivasi, keterampilan pemahaman, kemampuan pemecahan masalah matematika, strategi Think Talk Write

\section{ARTICLE HISTORY:}

Received: 2019-08-10, Revised: 2019-08-10,

Accepted: 2019-08-23, Onlinefirst: 2019-09-07

\section{PENDAHULUAN}

Pendidikan merupakan salah satu aspek sangat penting pada era globalisasi yang semakin penuh tantangan ini, karena dengan pendidikan diharapkan mampu membentuk sumber daya manusia yang kreatif, terampil dan inovatif (Lestari, 2015). Pada pendidikan di Indonesia, pendidikan formal adalah pendidikan utama dan matematika termasuk salah satu mata pelajaran yang ada di setiap jenjang pendidikan formal di Indonesia. Dalam keberhasilan suatu pembelajaran tentunya dapat dilihat pada proses pembelajaran.

Motivasi peserta didik dalam proses pembelajaran matematika tentunya sangat diperlukan agar proses pembelajaran dapat berlangsung dengan baik. Motivasi adalah sebuah dorongan internal dan eksternal dari diri seseorang untuk melakukan sebuah perubahan, yang memiliki indikator sebagai berikut: (1) adanya hasrat dan keinginan untuk melakukan suatu kegiatan, (2) adanya dorongan dan kebutuhan melakukan kegiatan, (3) adanya sebuah harapan dan cita-cita, (4) adanya penghargaan dan penghormatan atas diri sendiri, (5) lingkungan sekitar yang baik, (6) dilakukannya sebuah kegiatan yang menarik (Uno, 2013).

Keterampilan adalah sebuah perlakuan atau tindakan seseorang yang kompleks, memerlukan pengetahuan dan melibatkan kinerja (Susongko, 2017). Untuk mencapai konsep yang diharapkan, guru merupakan pembimbing peserta didik pada salah satu tujuan dari pemahaman matematika (Kusmanto, 2014). Keterampilan pada dasarnya akan lebih baik jika secara terus menerus diasah dan dilatih sehingga akan dapat lebih menguasai dari salah satu bidang keterampilan yang ada, khususnya dalam belajar matematika.

Motivasi dan keterampilan pemahaman merupakan faktor penunjang untuk 
kemampuan pemecahan masalah matematika peserta didik. Peserta didik lebih termotivasi dalam pembelajaran, tentunya akan menimbulkan pemahaman yang kuat dan dengan begitu akan mempermudah peserta didik dalam pemecahan masalah. Pemecahan masalah adalah suatu proses atau upaya untuk merespons atau mengatasi halangan atau kendala ketika suatu jawaban atau metode jawaban belum tampak jelas (Siswono, 2018).

Strategi dalam proses pembelajaran sangat diperlukan untuk mewujudkan pembelajaran yang diharapkan. Salah satu strategi pembelajaran yaitu strategi pembelajaran Think Talk Write. Strategi ini diawali dengan peserta didik membaca lembar kerja yang diserahkan oleh guru (think), kemudian peserta didik mendiskusikan dengan kelompoknya untuk mendapatkan kesamaan pemahaman (talk), dan diakhiri negosiasi peserta didik menuliskan hasil pemikirannya sendiri secara individu dalam bentuk rangkuman (write) (Winayawati dkk, 2012). Strategi dalam pembelajaran diharapkan mampu memberikan motivasi dan pemahaman peserta didik sehingga nantinya dapat membawa peserta didik ke dalam pemecahan masalah matematika.

Berdasarkan penelitian sebelumnya oleh (Utama, 2014), diperoleh kesimpulan bahwa motivasi belajar dan keterampilan pemahaman menunjang kemampuan pemahaman matematika dengan strategi pembelajaran Think Talk Write. Penelitian oleh (Kiswoyowati, 2011) kesimpulan penelitiannya adalah terdapat pengaruh yang positif motivasi belajar terhadap kegiatan belajar peserta didik. Selanjutnya penelitian oleh (Kusmanto, 2014) memperoleh kesimpulan bahwa pemahaman peserta didik berpengaruh terhadap kemampuan koneksi matematika.

\section{METODE PENELITIAN}

Penelitian ini merupakan jenis penelitian eksperimen korelasional. Hal ini dikarenakan pada penelitian ini akan melihat bagaimana hubungan suatu variabel yaitu motivasi dan keterampilan pemahaman sebagai variabel bebas atau Independent Variable dengan kemampuan pemecahan masalah matematika peserta didik sebagai variabel terikat atau Dependent Variable dengan strategi Think Talk Write. Penelitian eksperimen korelasional adalah peneliltian yang melibatkan hubungan antara variabel atau beberapa variabel dengan variabel lain (Zuriah, 2009).

Penelitian ini dilaksanakan di SMP Negeri 19 Tegal yang berlangsung pada 
tanggal 18 Maret 2019 sampai dengan tanggal 11 April 2019 selama 5 kali pertemuan dengan materi pokok segiempat. Populasinya adalah peserta didik kelas VII di SMP Negeri 19 Tegal sebanyak 7 kelas yang terdiri dari kelas VII A sampai dengan kelas VII G Semester Genap Tahun Ajaran 2018/2019. Teknik pengambilan sampel menggunakan Random Cluster Sampling. Teknik sampling daerah ini digunakan untuk menentukan sampel jika objek/subjek yang diteliti sangat luas (Lestari dkk, 2015). Diperoleh kelas VII D dan kelas VII E sebagai kelas eksperimen berjumlah 63 peserta didik, dan kelas VII C sebagai kelas uji coba berjumlah 32 peserta didik.

Metode pengumpulan data pada penelitian ini menggunakan dokumentasi, angket, observasi dan tes. Dokumentasi untuk memperoleh data nama dan kemampuan awal peserta didik yang berupa penilaian akhir semester 1 pada pembelajaran matematika kelas VII SMP Negeri 19 Tegal Tahun Pelajaran 2018/2019. Instrumen angket dan tes diberikan pada kelas uji coba sebelum nantinya diberikan pada kelas eksperimen. Observasi sebagai pengamatan keterampilan pemahaman dengan indikator pemahaman pengintegrasian. Teknik analisis data sebelum penelitian dilakukan uji normalitas dengan menggunakan uji liliefors, uji homogenitas dengan menggunakan uji barlett dan uji kesetaraan sampel dengan menggunakan anova satu arah, sedangkan pengujian setelah penelitian menggunakan uji normalitas dan uji normalitas sisa. Pengujian pada hipotesis pertama dan kedua yaitu dilakukan dengan uji regresi linier sederhana, sedangkan untuk hipotesis ketiga menggunakan uji regresi ganda.

\section{HASIL DAN PEMBAHASAN}

Tabel 1. Deskripsi data motivasi, keterampilan pemahaman, dan kemampuan pemecahan masalah matematika dengan strategi Think Talk Write

\begin{tabular}{cccc}
\hline Deskriptif & Motivasi & $\begin{array}{c}\text { Keterampilan } \\
\text { Pemahaman }\end{array}$ & $\begin{array}{c}\text { Kemampuan } \\
\text { Pemecahan Masalah }\end{array}$ \\
\hline Mean & 69,5873 & 69,2222 & 74,6667 \\
\hline Median & 67 & 70 & 76 \\
\hline Modus & 63 & 70 & 89 \\
\hline Tertinggi & 91 & 88 & 90 \\
\hline Terendah & 49 & 48 & 55 \\
\hline Standar Deviasi & 11,3189 & 10,8054 & 10,2941 \\
\hline Varian & 128,1173 & 116,7563 & 105,9677 \\
\hline
\end{tabular}


Berdasarkan tabel deskriptif di atas dapat diketahui bahwa nilai rata-rata data kemampuan pemecahan masalah matematika lebih tinggi dibanding dengan nilai data motivasi dan keterampilan pemahaman.

Tabel 2. Frekuensi relatif dari data motivasi

\begin{tabular}{ccc}
\hline $\begin{array}{c}\text { Skor } \\
\text { Motivasi }\end{array}$ & $\begin{array}{c}\text { Banyaknya } \\
\text { Peserta Didik }\end{array}$ & $\begin{array}{c}\text { Frekuensi } \\
\text { Relatif }\end{array}$ \\
\hline $49-54$ & 8 & $13 \%$ \\
\hline $55-60$ & 4 & $6 \%$ \\
\hline $61-66$ & 15 & $24 \%$ \\
\hline $67-72$ & 12 & $19 \%$ \\
\hline $73-78$ & 7 & $11 \%$ \\
\hline $79-84$ & 9 & $14 \%$ \\
\hline $85-90$ & 7 & $11 \%$ \\
\hline $91-96$ & 1 & $2 \%$ \\
\hline Jumlah & 63 & $100 \%$ \\
\hline
\end{tabular}

Berdasarkan Tabel 2 dapat disimpulkan bahwa motivasi peserta didik pada kelas eksperimen paling rendah pada interval 91 sampai dengan 96 dengan jumlah peserta didik sebaanyak 1 peserta didik, sedangkan interval paling paling tinggi yaitu pada interval 61 sampai dengan 66 dengan jumlah peerta didik sebanyak 12 peserta didik.

Tabel 3. Frekuensi relatif dari data keterampilan pemahaman

\begin{tabular}{ccc}
\hline $\begin{array}{c}\text { Skor Keterampilan } \\
\text { Pemahaman }\end{array}$ & $\begin{array}{c}\text { Banyaknya } \\
\text { Peserta Didik }\end{array}$ & $\begin{array}{c}\text { Frekuensi } \\
\text { Relatif }\end{array}$ \\
\hline $48-53$ & 6 & $10 \%$ \\
\hline $54-59$ & 8 & $13 \%$ \\
\hline $60-65$ & 7 & $11 \%$ \\
\hline $66-71$ & 13 & $21 \%$ \\
\hline $72-77$ & 10 & $16 \%$ \\
\hline $78-83$ & 14 & $22 \%$ \\
\hline $84-89$ & 5 & $8 \%$ \\
\hline Jumlah & 63 & $100 \%$ \\
\hline
\end{tabular}


Berdasarkan Tabel 3 dapat disimpulkan bahwa keterampilan pemahaman peserta didik pada kelas eksperimen paling rendah pada interval 84 sampai dengan 89 dengan jumlah peserta didik sebanyak 5 peserta didik, sedangkan interval paling paling tinggi yaitu pada interval 78 sampai dengan 83 dengan jumlah peserta didik sebanyak 14 peserta didik.

Tabel 4. Frekuensi relatif dari data kemampuan pemecahan masalah matematika dengan strategi Think Talk Write

\begin{tabular}{ccc}
\hline $\begin{array}{c}\text { Skor Kemampuan } \\
\text { Pemecahan Masalah }\end{array}$ & $\begin{array}{c}\text { Banyaknya } \\
\text { Peserta Didik }\end{array}$ & $\begin{array}{c}\text { Frekuensi } \\
\text { Relatif }\end{array}$ \\
\hline $55-59$ & 3 & $5 \%$ \\
\hline $60-64$ & 10 & $16 \%$ \\
\hline $65-69$ & 8 & $13 \%$ \\
\hline $70-74$ & 9 & $14 \%$ \\
\hline $75-79$ & 10 & $16 \%$ \\
\hline $80-84$ & 8 & $13 \%$ \\
\hline $85-89$ & 14 & $22 \%$ \\
\hline $90-94$ & 1 & $2 \%$ \\
\hline Jumlah & 63 & $100 \%$ \\
\hline
\end{tabular}

Berdasarkan Tabel 3 dapat disimpulkan bahwa kemampuan pemecahan masalah matematika peserta didik pada kelas eksperimen paling rendah pada interval 90 sampai dengan 94 dengan jumlah peserta didik sebaanyak 1 peserta didik, sedangkan interval paling paling tinggi yaitu pada interval 85 sampai dengan 89 dengan jumlah peerta didik sebanyak 14 peserta didik.

Tabel 5. Hasil uji normalitas dan normalitas sisa kelas eksperimen setelah penelitian

\begin{tabular}{cccc}
\hline Uji & $\boldsymbol{L}_{\text {hitung }}$ & $\boldsymbol{L}_{\text {tabel }}$ & Keterangan \\
\hline Normalitas & 0,0858 & 0,1116 & NORMAL \\
\hline Normalitas Sisa $X_{1}$ terhadap $Y$ & 0,1101 & 0,1116 & NORMAL \\
\hline Normalitas Sisa $X_{2}$ terhadap $Y$ & 0,1043 & 0,1116 & NORMAL \\
\hline Normalitas Sisa $X_{1}$ dan $X_{2}$ terhadap $Y$ & 0,0815 & 0,1116 & NORMAL
\end{tabular}

Berdasarkan data normalitas dan normalitas sisa untuk motivasi $\left(X_{1}\right)$ terhadap 
kemampuan pemecahan masalah matematika dengan strategi Think Talk Write $(Y)$, keterampilan pemahaman $\left(X_{2}\right)$ terhadap kemampuan pemecahan masalah matematika dengan strategi Think Talk Write $(Y)$, serta untuk motivasi $\left(X_{1}\right)$ dan keterampilan pemahaman $\left(X_{2}\right)$ terhadap kemampuan pemecahan masalah matematika dengan strategi Think Talk Write $(Y)$ menunjukan bahwa $L_{\text {hitung }}<L_{\text {tabel }}$ dengan taraf signifikan $5 \%$, sehingga dapat disimpulkan bahwa data kemampuan pemecahan masalah matematika peserta didik pada kelas eksperimen yang diajar dengan menggunakan strategi Think Talk Write berdistribusi normal dan residu untuk semua uji normalitas sisa berdistribusi normal.

Tabel 6. Hasil Uji Regresi Linear Sederhana $X_{1}$ terhadap $Y$

\begin{tabular}{cccccc}
\hline Sumber Variasi & $\boldsymbol{d} \boldsymbol{k}$ & $\mathbf{J K}$ & $\mathbf{R K}$ & $\boldsymbol{F}_{\text {hitung }}$ & $\boldsymbol{F}_{\text {tabel }}$ \\
\hline Total & 63 & 357802 & & & \\
\hline Regresi $(a)$ & 1 & 351232 & 351232 & 93,7951 & 3,9985 \\
\hline Regresi $(b \mid a)$ & 1 & 3980,9648 & 3980,9648 & & \\
\hline Residu & 61 & 2589,0352 & 42,4432 & & 1,8157 \\
\hline Tuna Cocok & 24 & 974,4018 & 40,6001 & 0,9304 & \\
\hline Galat & 37 & 1614,6333 & 43,6387 & & \\
\hline
\end{tabular}

Berdasarkan data di atas untuk uji keberartian diperoleh nilai $F_{\text {hitung }}=93,7951$ dan dengan taraf signifikansi $5 \% \mathrm{dk}$ pembilang $=1, \mathrm{dk}$ penyebut $=61$ diperoleh nilai $F_{\text {tabel }}=3$, 9989. Karena $F_{\text {hitung }}>F_{\text {tabel }}$ maka koefisien $\hat{Y}=25,4032+0,7079 X_{1}$ berarti. Serta untuk uji kelinearitas diperoleh $F_{\text {hitung }}=0,3914$ dengan taraf signifikan $5 \%$, dk pembilang $=24 \mathrm{dan} \mathrm{dk}$ penyebut $=37$ diperoleh $F_{\text {tabel }}=1,9036$. Karena $F_{\text {hitung }}<F_{\text {tabel }}$ maka model linear.

Selanjutnya untuk hasil uji korelasi dan regresi sederhana diperoleh hasil $r_{x y}=$ 0,7784 , koefisien determinasi 0,6059 dan $t_{\text {hitung }}=9,6848$. Untuk $t_{\text {tabel }}=1,9983$ dengan $\alpha=5 \%$ dan $\mathrm{dk}=63$. Maka $t_{\text {hitung }}>t_{\text {tabel }}$ berarti Ho ditolak, sehingga motivasi berpengaruh positif terhadap kemampuan pemecahan masalah matematika dengan strategi Think Talk Write. Besar pengaruhnya adalah 60,59\%. Seperti halnya pada penelitian yang sudah dilakukan oleh (Kriswoyowati, 2011) motivasi belajar juga 
berpengaruh terhadap kegiatan belajar peserta didik.

Tabel 7. Hasil Uji Regresi Linear Sederhana $X_{2}$ terhadap $Y$

\begin{tabular}{cccccc}
\hline Sumber Variasi & $\boldsymbol{d} \boldsymbol{k}$ & JK & RK & $\boldsymbol{F}_{\text {hitung }}$ & $\boldsymbol{F}_{\text {tabel }}$ \\
\hline Total & 63 & 357802 & & & \\
\hline Regresi $(a)$ & 1 & 351232 & 351232 & 88,8802 & 3,9985 \\
\hline Regresi $(b \mid a)$ & 1 & 3896,0648 & 3896,0648 & & \\
\hline Residu & 61 & 2673,9352 & 43,835 & & \\
\hline Tuna Cocok & 28 & $-932,9148$ & $-33,3184$ & $-0,3048$ & 1,8194 \\
\hline Galat & 33 & 3606,85 & 109,2985 & & \\
\hline
\end{tabular}

Berdasarkan data di atas untuk uji keberartian diperoleh nilai $F_{\text {hitung }}=88,8802$ dan dengan taraf signifikansi $5 \% \mathrm{dk}$ pembilang $=1$, dk penyebut $=61$ diperoleh nilai $F_{\text {tabel }}=3,9985$. Karena $F_{\text {hitung }}>F_{\text {tabel }}$ maka koefisien $\hat{Y}=23,8832+0,7336 X_{2}$ berarti. Serta untuk uji kelinearitas diperoleh $F_{\text {hitung }}=-0,3048$ dengan taraf signifikan 5\%, dk pembilang $=28$ dan dk penyebut $=33$ diperoleh $F_{\text {tabel }}=1,8194$. Karena $F_{\text {hitung }}<F_{\text {tabel }}$ maka model linear.

Selanjutnya untuk hasil uji korelasi dan regresi sederhana diperoleh hasil $r_{x y}=$ 0,7701 , koefisien determinasi 0,5930 dan $t_{\text {hitung }}=9,4276$. Untuk $t_{\text {tabel }}=1,9983$ dengan $\alpha=5 \%$ dan $\mathrm{dk}=63$. Maka $t_{\text {hitung }}>t_{\text {tabel }}$ berarti Ho ditolak, sehingga keterampilan pemahaman berpengaruh positif terhadap kemampuan pemecahan masalah matematika dengan strategi Think Talk Write. Besar pengaruhnya adalah $59,3 \%$. Seperti halnya pada penelitian yang sudah dilakukan oleh (Kusmanto, 2014) memperoleh kesimpulan bahwa pemahaman peserta didik berpengaruh terhadap kemampuan koneksi matematika.

Uji regresi ganda sebelum dilakukan, perlu adanya uji asumsi regresi yaitu uji multikolinearitas, autokorelasi dan heteroskedastisitas.

a. Multikolinearitas

Uji multikolinearitas antara motivasi $\left(X_{1}\right)$ dengan keterampilan pemahaman $\left(X_{2}\right)$ diperoleh nilai $t_{\text {hitung }}=11,0741$ dengan menggunakan 
taraf signifikansi $\alpha=5 \%$ dan $n-k=61$, diperoleh $t_{\text {tabel }}=1,6694$ maka $t_{\text {hitung }}>t_{\text {tabel }}$ dapat disimpulkan bahwa tidak terjadi multikolinearitas antara motivasi $\left(X_{1}\right)$ dan keterampilan pemahaman $\left(X_{2}\right)$.

b. Autokorelasi

Berdasarkan hasil olah data dengan SPSS 17, diperoleh output sebagai berikut:

Model Summary
\begin{tabular}{|l|c|c|c|c|c|}
\hline Model & $\mathrm{R}$ & $\mathrm{R}$ Square & $\begin{array}{c}\text { Adjusted R } \\
\text { Square }\end{array}$ & $\begin{array}{c}\text { Std. Error of } \\
\text { the Estimate }\end{array}$ & $\begin{array}{c}\text { Durbin- } \\
\text { Watson }\end{array}$ \\
\hline 1 & $.845^{\mathrm{a}}$ & .713 & .704 & 5.88079 & 1.790 \\
\hline
\end{tabular}
a. Predictors: (Constant), KETERAMPILAN PEMAHMAN, MOTIVASI
b. Dependent Variable: KEMAMPUAN PEMECAHAN MASALAH

\section{Gambar 1. Model Summary}

Berdasarkan gambar nampak nilai Durbin-Watson $=1,790$. Nilai tersebut berada dalam interval $-2 \leq D W \leq 2$. Maka tidak ada autokorelasi antara motivasi $\left(X_{1}\right)$ dan keterampilan pemahaman $\left(X_{2}\right)$.

c. Heterokedastisitas

Berdasarkan hasil olah data dengan SPSS 17, diperoleh output sebagai berikut:

Charts

Scatterplot

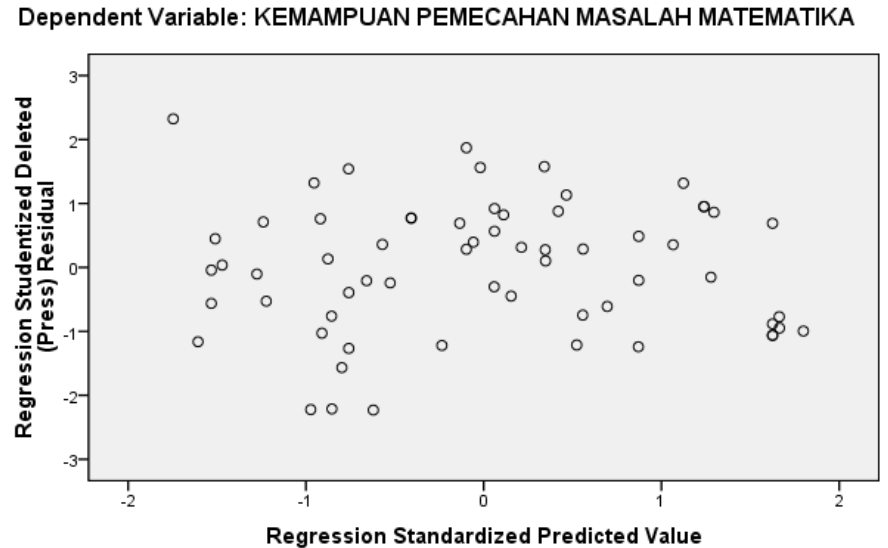

Gambar 2. Scatterplot

Terlihat bahwa titik-titik yang terjadi cukup menyebar di sekitar garis 
nol, ada yang di atas garis nol dan ada pula yang di bawah garis nol. Hal ini menunjukkan pola tertentu jadi tida terjadi heterokedasitas antara motivasi $\left(X_{1}\right)$ dan keterampilan pemahaman $\left(X_{2}\right)$

Selanjutnya setelah dilakukan uji asumsi regresi tidak terjadi multikolinearitas, autokorelasi dan heteroskedastisitas maka langkah selanjutnya adalah menghitung uji regresi ganda.

Tabel 8. Uji regresi ganda

\begin{tabular}{llrlrl}
\hline SUMBER & JK & Dk & \multicolumn{1}{l}{ RK } & $\boldsymbol{F}_{\text {hitung }}$ & $\boldsymbol{F}_{\text {tabel }}$ \\
\hline Regresi & 4335,8239 & 2 & 2167,912 & 58,2204 & 3,1504 \\
\hline Sisa & 2234,1761 & 60 & 37,2363 & & \\
\hline Total & 6570 & 61 & & & \\
\hline
\end{tabular}

Dari tabel diperoleh $F_{\text {hitung }}=58,2204$ dengan taraf signifikansi $5 \%$ dk pembilang $=2$, dk penyebut $=60$, diperoleh $F_{\text {tabel }}=3,1504$. Karena $F_{\text {hitung }}>F_{\text {tabel }}$ maka modelnya linear.

Selanjutnya berdasarkan perhitungan diperoleh hasil $r_{(1,2) y}=0,8124$ koefisien determinasi 0,6599 dan $F_{\text {hitung }}=58,2204$. Untuk $F_{\text {tabel }}=3,1504$ dengan $\alpha=5 \%$ dan $\mathrm{dk}=63$. Maka $F_{\text {hitung }}>F_{\text {tabel }}$ berarti Ho ditolak, sehingga motivasi dan keterampilan pemahaman berpengaruh positif terhadap kemampuan pemecahan masalah matematika dengan strategi Think Talk Write. Besar pengaruhnya adalah 65,99\%. Seperti halnya pada penelitian yang sudah dilakukan oleh (Utama, 2014) di SMA Muhammadiyah Pemalang dimana dalam penelitiannya motivasi dan keterampilan pemahaman berpengaruh positif terhadap kemampuan pemahaman matematika.

\section{SIMPULAN DAN SARAN}

Berdasakan analisis data yang telah dilakukan, maka dapat diperoleh simpulan yang pertama yaitu terdapat pengaruh positif motivasi belajar matematika pesert didik pada materi segiempat terhadap kemampuan pemecahan masalah matematika dengan besar pengaruhnya adalah $60,59 \%$. Kedua yaitu terdapat pengaruh positif keterampilan pemahaman matematika dengan indikator pemahaman pesert didik pada materi segiempat terhadap kemampuan pemecahan masalah matematika dengan besar 
pengaruhnya adalah 59,3\%, dan yang ketiga adalah terdapat pengaruh positif motivasi belajar matematika pesert didik pada materi segiempat dan keterampilan pemahaman matematika dengan indikator pemahaman pesert didik pada materi segiempat terhadap kemampuan pemecahan masalah matematika dengan besar pengaruhnya adalah 65,99\%.

Berdasarkan penelitian yang sudah dilakukan terdapat beberapa saran yang perlu diperhatikan untuk penelitian sejenis selanjutnya antara lain:

1. Guru hendaknya menerapkan strategi yang sesuai untuk pembelajaran agar peserta didik lebih termotivasi dalam pembelajaran.

2. Strategi pembelajaran Think Talk Write dapat djadikan salah satu alternatif pembelajaran matematika di kelas-kelas agar peserta didik tidak merasa bosan dengan strategi pembelajaran yang sering digunakan dalam pembelajaran.

3. Pada penelitian ini, satu observer hanya mengamati beberapa peserta didik saja dan tidak mengamati keseluruhan peserta didik. Sebaiknya untuk penelitian selanjutnya, observer selain mengamati beberapa peserta didik juga harus mengamati keseluruhan peserta didik agar data yang diperoleh benarbenar relevan.

\section{DAFTAR PUSTAKA}

Kiswoyowati, A. 2011 Pengaruh Motivasi Belajar dan Kegiatan Belajar Peserta Didik terhadap Kecakapan Hidup Peserta Didik. Portal Jurnal Universitas Pendidikan Indonesia, 2(1), 12-16.

Kusmanto, H. 2014. Pengaruh Pemahaman Matematika Terhadap Kemampuan Koneksi Matematika Peserta Didik Kelas VII Semester Genap SMP Negeri 2 Kasokandel Kabupaten Majalengka. Eduma: Mathematics Education Learning and Teaching, 3(2).

Lestari, K. E. \& Mokhammad, R. Y. 2015. Penelitian Pendidikan Matematika. Bandung: Refika Aditama.

Lestari, W. 2015. Efektifitas Strategi Pembelajaran dan Motivasi Belajar terhadap Hasil Belajar Matematika. Formatif: Jurnal Ilmiah Pendidikan MIPA, 2(3).

Siswono, Tatag Y. E. 2018. Pembelajaran Matematika Berbasis Pengajuan Dan Pemecahan Masalah. Bandung: Remaja Rosdakarya.

Sugiyono. 2015. Statistika Untuk Penelitian. Bandung: Alfabeta. 
Susongko, P. 2017. Penilaian Hasil Belajar. Tegal: Universitas Pancasakti Tegal.

Uno, Hamzah B. 2013. Teori Motivasi Dan Pengukurannya. Jakarta: Bumi Aksara.

Utama, Mahatva Y. 2014. Pengaruh Motivasi Dan Keterampilan Pemahaman Terhadap Kemampuan Pemahaman Matematika Dengan Strategi Think Talk Write. Disertasi Universitas Pancasakti Tegal.

Winayawati, L., Waluya, S. B., \& Junaedi, I. 2012. Implementasi Model Pembelajaran Kooperatif dengan Strategi Think-Talk-Write terhadap Kemampuan Menulis Rangkuman dan Pemahaman Matematis Materi Integral. Unnes Journal of Mathematics Education Research, 1(1).

Zuriah, N. 2009. Metodologi Penelitian Sosial Dan Pendidikan Teori-Aplikasi. Jakarta: Bumi Aksara. 